\title{
Effect of Shared Electronic Health Records on Duplicate Imaging after Hospital Transfer
}

\author{
Benjamin N. Rome, $M D^{1,2}(\mathbb{D})$ Jeffrey L. Schnipper, $M D, M P H^{2,3}$, \\ Saverio M. Maviglia, MD, MS 2,3,4, and Stephanie K. Mueller, MD, MPH ${ }^{2,3}$
}

'Program on Regulation, Therapeutics, and Law, Brigham and Women's Hospital, Boston, MA, USA; ${ }^{2}$ Harvard Medical School, Boston, MA, USA; ${ }^{3}$ Division of General Internal Medicine, Brigham and Women's Hospital, Boston, MA, USA; ${ }^{4}$ Department of Medicine, South Shore Hospital, Weymouth, MA, USA.

J Gen Intern Med 35(5):1617-19

DOI: $10.1007 / \mathrm{s} 11606-019-05355-2$

(c) Society of General Internal Medicine 2019

I nterhospital transfer (IHT) may lead to gaps in information between transferring and receiving care teams. Transferred patients experience higher cost per hospital day than nontransferred patients, which may be partially explained by incomplete information exchange leading to duplicate testing. ${ }^{1,} 2$ Electronic health record (EHR) interoperability presents a possible solution, allowing for instant transfer of clinical information and reducing the need to order duplicate tests. ${ }^{3,4}$ We evaluated whether the implementation of a shared EHR reduced duplicate diagnostic imaging during IHT.

\section{METHODS}

We performed a retrospective, pre-post study involving patients transferred from a community hospital to a tertiary care hospital in Massachusetts. We included all inpatients transferred to general medicine, oncology, or cardiology services in the year before and after implementation of a shared EHR (July 2017).

The primary outcome was odds of transfer with at least one duplicate imaging study. For each computed tomography (CT), magnetic resonance imaging, transthoracic echocardiogram (TTE), and non-TTE ultrasound ordered within $48 \mathrm{~h}$ after transfer, we used chart review to determine if a duplicate study - defined as same modality and body area — had been performed within 7 days prior to transfer. We also used two stricter definitions of duplicate images: (1) studies that utilized similar technique (e.g., contrast vs non-contrast CT) and (2) studies without a documented clinical reason.

We used chi-squared and $t$ tests to compare patient characteristics pre- versus post-shared EHR. We used univariate and multivariate logistic regression to obtain the odds of transfer

Received July 31, 2019

Accepted September 11, 2019

Published online October 24, 2019 with duplicate imaging post- versus pre-shared EHR, adjusting for demographics, admission service, calendar quarter (to account for residency training effects and seasonal case mix variation), and comorbidity and to identify independent predictors of duplicate imaging. All analyses were performed in Stata 15 (StataCorp, College Station, TX).

\section{RESULTS}

We identified 109 patient transfers in the year before and 92 patients in the year after shared EHR implementation. Patient demographics, transfer characteristics, and illness severity were similar between the two groups. A total of 209 imaging studies were ordered after transfer, of which 59 (28.2\%) were duplicates.

Our primary analysis demonstrated a non-significant trend toward decreased adjusted odds of duplicate imaging, postversus pre-shared EHR (Table 1). Results were similar using both stricter definitions of duplicate imaging.

Transfers to the cardiology service, transfers of white nonHispanic patients, and transfers during October-December (compared with July-September) were associated with increased adjusted odds of transfer with duplicate imaging (Table 2).

\section{DISCUSSION}

We did not detect a significant difference in duplicate imaging after transfer following the implementation of a shared EHR. Though the $37 \%$ observed reduction would be clinically meaningful, this study was underpowered to show this difference. Larger studies are needed to explore the potential for increased EHR interoperability to mitigate unnecessary resource utilization during IHT.

We found that 1 in 4 transferred patients underwent duplicate imaging, consistent with prior studies of Emergency Room and pediatric patient transfers. ${ }^{4,5}$ While some duplicate imaging may be clinically necessary, we only found supportive documentation for one-third of studies, suggesting that most may be unnecessary and potentially avoidable.

White non-Hispanic patients had greater adjusted odds of undergoing duplicate imaging, which supports prior findings 
Table 1 Frequency of Duplicate Images Before and after Implementation of a Shared EHR

\begin{tabular}{|c|c|c|c|c|}
\hline & \multicolumn{2}{|c|}{$\begin{array}{l}\text { Frequency of at least one duplicate } \\
\text { imaging study after transfer, } N(\%)\end{array}$} & \multicolumn{2}{|c|}{$\begin{array}{l}\text { Odds ratio, post- versus pre-shared } \\
\text { EHR, OR (95\% CI) }\end{array}$} \\
\hline & $\begin{array}{l}\text { Pre-shared EHR } \\
(N=109)\end{array}$ & $\begin{array}{l}\text { Post-shared EHR } \\
(N=92)\end{array}$ & Unadjusted & Adjusted* \\
\hline \multicolumn{5}{|l|}{ Primary analysis } \\
\hline Baseline definition of duplicate images & $32(29.4 \%)$ & $19(20.7 \%)$ & $0.63(0.33,1.20)$ & $0.66(0.32,1.36)$ \\
\hline \multicolumn{5}{|l|}{ Secondary analyses } \\
\hline Stricter definition of duplicate images ${ }^{\dagger}$ & $28(25.7 \%)$ & $18(19.6 \%)$ & $0.70(0.36,1.38)$ & $0.75(0.36,1.57)$ \\
\hline Duplicate images without clinical reason provided & $24(22.0 \%)$ & $13(14.1 \%)$ & $0.58(0.28,1.22)$ & $0.62(0.28,1.39)$ \\
\hline
\end{tabular}

CI, confidence interval; EHR, Electronic Health Record; OR, odds ratio

*Adjusted for patient age, sex, racelethnicity, insurance, admission service, calendar quarter, Elixhauser Comorbidity Index, and APR-DRG weight

†Duplicate image defined as same technique (e.g., "with contrast" versus "without contrast"), in addition to baseline definition (same modality and body part)

of racial disparities within IHT. $^{6}$ We also noted more duplicate imaging among cardiology transfers and seasonal effects of unclear significance.

Notably, the shared EHR we studied allowed review of imaging reports but not actual images. Digital sharing of radiology images between hospitals may be necessary to further reduce unnecessary duplicate testing.

Our study was limited to examining transfers between a single community hospital and academic medical center, but given the known high frequency of redundant testing during IHT, our findings may be applicable to similar institutions.

Table 2 Predictors of at Hospital Transfer with at Least One Duplicate Image

\begin{tabular}{|c|c|c|}
\hline Variable & $\begin{array}{l}\text { Unadjusted } \\
\text { OR }\end{array}$ & $\begin{array}{l}\text { Adjusted OR } \\
(95 \% \text { CI })^{*}\end{array}$ \\
\hline \multicolumn{3}{|l|}{ Time period } \\
\hline Pre-shared EHR & Reference & Reference \\
\hline Post-shared EHR & $0.63(0.33,1.20)$ & $0.66(0.32,1.36)$ \\
\hline Age, per year & $1.00(0.98,1.03)$ & $0.98(0.95,1.01)$ \\
\hline \multicolumn{3}{|l|}{ Sex } \\
\hline Male & Reference & Reference \\
\hline Female & $1.20(0.63,2.27)$ & $1.59(0.68,2.73)$ \\
\hline \multicolumn{3}{|l|}{ Race/ethnicity } \\
\hline Other $^{\dagger}$ & Reference & Reference \\
\hline White, non-Hispanic & $4.55(1.32,16.67)$ & $3.70(1.00,12.5)$ \\
\hline \multicolumn{3}{|l|}{ Insurance } \\
\hline Commercial & Reference & Reference \\
\hline Other & $1.12(0.58,2.20)$ & $1.10(0.47,2.59)$ \\
\hline \multicolumn{3}{|l|}{ Admission service } \\
\hline Medicine, oncology & Reference & Reference \\
\hline Cardiology & $4.60(1.84,11.46)$ & $4.25(1.60,11.31)$ \\
\hline \multicolumn{3}{|l|}{ Admission date } \\
\hline July-September & Reference & Reference \\
\hline October-December & $3.43(1.27,9.27)$ & $3.64(1.20,11.01)$ \\
\hline January-March & $1.70(0.60,4.79)$ & $1.52(0.50,4.62)$ \\
\hline April-June & $0.83(0.29,2.40)$ & $0.79(0.25,2.48)$ \\
\hline Elixhauser Comorbidity & $0.97(0.82,1.14)$ & $1.02(0.98,1.06)$ \\
\hline $\begin{array}{l}\text { Index, per point } \\
\text { APR-DRG weight, per point }\end{array}$ & $1.00(0.97,1.03)$ & $0.91(0.76,1.10)$ \\
\hline
\end{tabular}

*Each variable adjusted for all other variables shown in the table. Italicized values are statistically significant $(p<0.05)$

${ }^{\dagger}$ Includes Hispanic, Black or African American, Asian, or unavailable

${ }^{7}$ Includes Medicare, Medicaid, and other

OR, odds ratio; EHR, Electronic Health Record; APR-DRG, All Patients Refined Diagnosis-Related Group
Additionally, we evaluated the year immediately following shared EHR implementation; duplicate testing may drop further once clinicians become more familiar with the capabilities of health information exchange. Lastly, our methodology is subject to confounding by temporal trends, though we are unaware of any cointerventions.

\section{CONCLUSION}

Duplicate imaging studies are common after IHT. While we did not detect a significant reduction in duplicate imaging after shared EHR implementation, the results of our study suggest the potential of health information exchange and indicate the need for larger studies to investigate whether real-time electronic clinical data sharing may reduce unnecessary resource utilization after transfer.

Acknowledgments: The authors thank Julie Fiskio for her assistance obtaining administrative data.

Corresponding Author: Benjamin N. Rome, MD; Program on Regulation, Therapeutics, and Law, Brigham and Women's Hospital, Boston, MA, USA (e-mail: brome@bwh.harvard.edu).

\section{Compliance with Ethical Standards:}

Conflict of Interest: The authors declare that they do not have a conflict of interest.

\section{REFERENCES}

1. Mueller S, Zheng J, Orav EJ, Schnipper JL. Inter-hospital transfer and patient outcomes: a retrospective cohort study. BMJ Qual Saf. 2018. https://doi.org/10.1136/bmjqs-2018-008087.

2. Mueller SK, Shannon E, Dalal A, Schnipper JL, Dykes P. Patient and physician experience with interhospital transfer: a qualitative study. J Patient Saf. https://doi.org/10.1097/PTS.0000000000000501.

3. Hillestad R, Bigelow J, Bower A, et al. Can electronic medical record systems transform health care? Potential health benefits, savings, and costs. Health Aff (Millwood). 24(5):1103-1117. https://doi.org/10.1377/ hlthaff.24.5.1103.

4. Stewart BA, Fernandes S, Rodriguez-Huertas E, Landzberg M. A preliminary look at duplicate testing associated with lack of electronic health record interoperability for transferred patients. J Am Med Inform 
Assoc. 2010;17(3):341-344. https://doi.org/10.1136/jamia.2009. 001750.

5. Watson JJJ, Moren A, Diggs B, et al. A statewide teleradiology system reduces radiation exposure and charges in transferred trauma patients. Am J Surg. 2016;211(5):908-912. https://doi.org/10.1016/j.amjsurg. 2016.01.010.
6. Mueller SK, Zheng J, Orav EJ, Schnipper JL. Rates, predictors and variability of interhospital transfers: a national evaluation. J Hosp Med. 2017;12(6):435-442. https://doi.org/10.12788/jhm.2747.

Publisher's Note Springer Nature remains neutral with regard to jurisdictional claims in published maps and institutional affiliations. 